Www.jmscr.igmpublication.org

Index Copernicus Value: 79.54

ISSN (e)-2347-176x ISSN (p) 2455-0450

crossrefDOI: https://dx.doi.org/10.18535/jmscr/v7i2.135

\title{
Correlation of inflammatory marker High-sensitive C-reactive protein (Hs-CRP) with risk factors of nephropathy in type 2 diabetes
}

\author{
Author \\ Surendra Prasad Singh \\ Department of Community Medicine, Patna Medical College \& Hospital, Patna, Bihar, India
}

\begin{abstract}
Aim: The goal of this observational trial is to evaluate the Correlation of inflammatory marker High-sensitive Creactive protein with risk factors of nephropathy in type 2 diabetes.

Methods: 82 type 2 diabetes patients (T2DM) was selected to conduct the observational study. A standard questionnaire was used to collect the data regarding major environmental risk factor for diabetic nephropathy of T2DM like age, duration of diabetes, smoking, anti-diabetic medication and anti-hypertensive medication. Blood sample was collected to perform pathological test like Fasting Plasma Glucose (FPG), Post Prandial Plasma glucose $(P P G)$ and high sensitive $C$ reactive protein $(H s-C R P)$.

Result: Result of this observational study reveals that the risk factors for diabetic nephropathy of T2DM like age $(p=0.231)$, duration of diabetes $(p=0.342)$, smoking $(p=0.931)$, anti-diabetic medication $(p=0.537)$ and antihypertensive medication ( $p=0.425$ ) was not found to be correlated with Hs-CRP levels.

Conclusion: This study concludes that inflammatory marker High-sensitive C-reactive protein insignificantly correlated with the major environmental risk factor for diabetic nephropathy of T2DMlike age, duration of diabetes, smoking, anti-diabetic medication and anti-hypertensive medication.

Keywords: Hs-CRP, Diabetic nephropathy, T2DM, Risk factors.
\end{abstract}

\section{Introduction}

Diabetes mellitus may be defined as a metabolic disorder characterized by hyperglycemia which leads to chronic complications such as diabetic nephropathy and cardiovascular diseases. These complications usually appear in the second decade of the hyperglycemia and the risk increases with the severity of hyperglycemia ${ }^{[1]}$. Incidence of Type 2 diabetes is enhancing globally and has reached wide ranging proportions in many countries. The recent evaluation by the International Diabetes Federation (IDF) revealed the number of people affected by the diabetes mellitus was 382 million which is predicted to increase to 592 million by 2035. IDF also estimated that about $8.3 \%$ of world population and
65.1 million of adult people in India are affected by diabetes ${ }^{[2]}$. A large body of data showed that the prevalence of Type 2 diabetes varies considerably between urban and rural populations and reveal the prevalence of diabetes has increased to $18.6 \%$ in urban and $9.2 \%$ in rural population in India with significant regional variations $^{[3]}$.

The goal of this observational trial is to evaluate the Correlation of inflammatory marker Highsensitive C-reactive protein with risk factors of nephropathy in type 2 diabetes.

\section{Methods}

This was an observational study conducted in Patna Medical College and Hospital. 82 type 2 
diabetes patients (T2DM) was selected to conduct the observational study. A standard questionnaire was used to collect the data regarding major environmental risk factor for diabetic nephropathy of T2DM like age, duration of diabetes, smoking, anti-diabetic medication and anti-hypertensive medication. Blood sample was collected to perform pathological test like Fasting Plasma Glucose (FPG), Post Prandial Plasma glucose (PPG) and high sensitive $\mathrm{C}$ reactive protein (HsCRP).

Personal interview was conducted using by a predesigned questionnaire containing dietary habit, family history, smoking, age, duration of diabetes, smoking, past medical history, complication of T2DM anti-diabetic medication and anti-hypertensive medication.

Table 1 Biochemical characteristics of the risk factors of diabetic nephropathy

\begin{tabular}{|l|c|c|c|c|c|}
\hline Parameter & Low & Normal & High & Total & P value \\
\hline FPG & 0 & 24 & 58 & 82 & 0.128 \\
\hline PPG & 0 & 24 & 58 & 82 & 0.534 \\
\hline Hs-CRP & 41 & 26 & 21 & 82 & 0.983 \\
\hline
\end{tabular}

This study reveals that the risk factors for diabetic nephropathy of T2DM like age $(\mathrm{p}=0.724)$, duration of diabetes $(\mathrm{p}=0.493)$, smoking $(\mathrm{p}=0.625)$, anti-diabetic medication $(\mathrm{p}=0.369)$ and anti-hypertensive medication $(\mathrm{p}=0.318)$ was not found to be correlated with Hs-CRP levels (Table 2). Table 2 shows the association of serum hsCRP with the risk factors of nephropathy. No significant association was found between serum hs-CRP level and the environment risk factors.

Table 2 Association of serum hs-CRP with the environmental risk factors of nephropathy.

\begin{tabular}{|c|c|c|c|c|}
\hline \multirow[t]{2}{*}{ Variables } & \multicolumn{3}{|c|}{ Hs-CRP value } & \multirow[t]{2}{*}{ P Value } \\
\hline & High Risk & Low Risk & Moderate & \\
\hline \multicolumn{5}{|l|}{ Diet } \\
\hline Vegetarian & 1 & 5 & 2 & \multirow[t]{2}{*}{0.515} \\
\hline Non vegetarian & 20 & 35 & 19 & \\
\hline \multicolumn{5}{|l|}{ Age of patients } \\
\hline 30 - 59 years & 4 & 10 & 3 & \multirow[t]{2}{*}{0.724} \\
\hline$\geq 60$ years & 16 & 30 & 19 & \\
\hline \multicolumn{5}{|l|}{ Smoking } \\
\hline Smoker & 6 & 6 & 1 & \multirow[t]{3}{*}{0.625} \\
\hline Non smoker & 12 & 34 & 16 & \\
\hline Previous smoker & 1 & 2 & 4 & \\
\hline \multicolumn{5}{|l|}{ Drinking Alcohol } \\
\hline Alcoholic & 2 & 3 & 3 & \multirow[t]{3}{*}{0.126} \\
\hline Non alcoholic & 13 & 33 & 13 & \\
\hline Previous alcoholic & 4 & 6 & 4 & \\
\hline \multicolumn{5}{|c|}{ Duration of diabetes } \\
\hline 1 year duration & 2 & 1 & 3 & \multirow[t]{3}{*}{0.493} \\
\hline Less than 10 yrs & 14 & 33 & 14 & \\
\hline Greater than $10 y r s$ & 4 & 7 & 3 & \\
\hline \multicolumn{5}{|c|}{ Medication of diabetes } \\
\hline Oral medication & 15 & 35 & 17 & \multirow[t]{3}{*}{0.369} \\
\hline Receiving insulin & 1 & 0 & 1 & \\
\hline No medicine & 3 & 6 & 3 & \\
\hline \multicolumn{5}{|c|}{ Pressure medication } \\
\hline Yes & 12 & 25 & 12 & \multirow[t]{2}{*}{0.318} \\
\hline No & 6 & 16 & 10 & \\
\hline
\end{tabular}




\section{Discussion}

Several recent studies have shown that the patients suffering from type $2 \mathrm{DM}$ and nephropathy exhibit high levels of diverse acute-phase markers of inflammation including CRP, serum amyloid A, fibrinogen and IL-6 $\left.6^{[4}-7\right]$. One study has reported that $96.2 \%$ of the type 2 diabetic nephropathy patients have raised CRP levels ${ }^{[8]}$. These evidences prove that the subclinical chronic inflammation is involved in the pathogenesis of diabetic nephropathy ${ }^{[9]}$. Similar finding of hs-CRP level was recorded in our study.

Hyperglycemia is a precondition for developing glomerular basement membrane (GBM) thickening and meningeal expansion, which may not present during early stage of diabetes but can be diagnosed 2 to 5years after onset of hyperglycemia. In chronic hyperglycemia, nonenzymatic glycation of amino acids, lipids and lipoproteins may occur. The formation of advanced glycation end-products (AGEs) has long been recognized as a fundamental mechanism of cellular injury in diabetes. The accumulation of AGEs accelerates atherogenesis, basement membrane thickening, increased extracellular matrix, and meningeal fibrosis. This process leads to eventual glomerulosclerosis and renal failure ${ }^{[10,}$ $11,12]$

Our study was revealed insignificant association of smoking, age of diabetic patients, diet, medication of diabetes, and alcoholic habit of the patients with serum hs-CRP level in type 2 diabetic patients; however, one trial ${ }^{[13]}$ showed that there was significant association between them. In the same way, our research revealed that there was no significant association between blood pressure medications with the risk of development of nephropathy, as described by Baluch et al, showed the similar result. We also found that there was insignificant association between serum hs-CRP levels and blood pressure medication.

\section{Conclusion}

This study concludes that inflammatory marker High-sensitive C-reactive protein insignificantly correlated with the major environmental risk factor for diabetic nephropathy of T2DM like age, duration of diabetes, smoking, anti-diabetic medication and anti-hypertensive medication.

\section{Disclosure}

The authors report no conflicts of interest in this work. No funding sources.

\section{Reference}

1. Shivananda NB, Geetha B. Relationship between sialic acid and metabolic variables in Indian type 2 diabetic patients. Lipids Health Dis. 2005;4:15.

2. Guariguata L, Nolan $T$, Beagley $T$, Linnenkamp U, Jacqmain O. The IDF Diabetes Atlas. 6th edition. IntDiab Feder.s; 2013. (Editors) pp. 19-34.

3. Jayawardena R, Ranasinghe P, Byrne Prevalence and trends of the diabetes epidemic in South Asia: a systematic review and meta-analysis. BMC Public Health. 2012;12:380.

4. Chen-Chun F, Y-ML, Li JC, Wu DA (2003). Association of $\mathrm{C}$ reactive protein and Traditional risk factors with nephropathy in the elderly patients with diabetes. Taiwan Geriatric and Gerontology, 3: 202-210.

5. Crook M (2004). Type 2 Diabetes mellitus: a disease of the innate immune system? an update. Diabetes Medication, 21: 203-207.

6. Mittal SB, Kumar A, Chandrasekharan N, Sunka A (2010). Diabetes mellitus as a potential risk factor for renal disease among Nepalese. Nepal Journal of Epidemiology, 1: 22-25.

7. Jiji I (2013). Role of duration of diabetes in the development of nephropathy in type 2 diabetic patients. National Journal of Medical research, 3: 1-8.

8. Khalaf SJ (2010). Study of some biochemical markers in diabetic patients. Tikrit Medical Journal, 16: 84-87. 
9. Choudhary TA, Lasker SS (2002). Complication and Cardiovascular risk factors in South Asian and Europeans with early- onset type 2 diabetes. QJM: International Journal of Medicine 95: 241246.

10. Martha RM, Femando GR (1999). Increased level of CRP in Non-controlled type II diabetic subjects. Journal of Diabetes and Its Complications, 13: 211215.

11. Pasceri VWJYE (2000). Direct proinflammatory effect of C-reactive protein on human Endothelial cells. Circulation, 102: 2165-2168.

12. Venugopal SK, Yuhanna I, Shaul P (2002). Demonstration that C-reactive protein decrease eNOS expression and bioactivity in human aortic endothelial cells. Circulation, 106: 1439-1441.

13. Crook M (2004). Type 2 Diabetes mellitus: a disease of the innate immune system? an update. Diabetes Medication, 21: 203-207.

14. Baluch UT, Niazi R, Bilal N, Tahir F (2011). C-reactive protein as a low grade inflammatory marker in type 2 diabetic nephropathy. Annals of Pakistan Institute of Medical Science, 7: 217-221. 